\title{
Gaucher Disease - A Rare Cause of Collodion
}

\author{
Zhi Xuen Low ${ }^{1} \cdot$ Gopakumar Hariharan ${ }^{2}$ (D)
}

Received: 3 August 2019 / Accepted: 22 August 2019/Published online: 16 September 2019

(C) Dr. K C Chaudhuri Foundation 2019

To the Editor: A baby boy, twin 2 of a dichorionic diamniotic (DCDA) twin pregnancy was noted to have ascites, hydrocele and small pericardial effusion antenatally. At birth, the baby had tight shiny skin with absent skin creases (Collodion), blueberry muffin spots, everted eyelids, abdominal distension, hepatosplenomegaly and hydrocele.

Initial investigations at birth revealed persistent thrombocytopenia without coagulopathy with a platelet count of $26 \times 10^{9} / \mathrm{L}$ (normal $100-500 \times 10^{9} / \mathrm{L}$ ) on day one of life and conjugated hyperbilirubinemia. Viral studies to rule out congenital infections, cranial and cardiac ultrasound were normal. An abdominal ultrasound confirmed mild to moderate hepatosplenomegaly. Ferritin level was $1021 \mu \mathrm{g} / \mathrm{L}$ (normal 10-336 $\mu \mathrm{g} / \mathrm{L}$ ).

Investigations for metabolic disorders showed a mild increase in ammonia of $55 \mu \mathrm{mol} / \mathrm{L}(16-50 \mu \mathrm{mol} / \mathrm{L})$ and markedly raised glucosyl sphingosine of $2620 \mathrm{nmol} / \mathrm{L}$ (normal $<10 \mathrm{nmol} / \mathrm{L}$ ). Dried blood spot lysosomal enzyme analysis showed reduced $\beta$-glucocerebrosidase of $0.2 \mu \mathrm{mol} / \mathrm{h} / \mathrm{L}$ (normal $2.5-8.5 \mu \mathrm{mol} / \mathrm{h} /$ L) and elevated chitotriosidase of $71 \mathrm{nmol} / \mathrm{h} / \mathrm{ml}$ (normal 2$50 \mathrm{nmol} / \mathrm{h} / \mathrm{ml}$ ) confirming the diagnosis of lethal variant of Type 2 congenital Gaucher disease. Gaucher disease variant analysis revealed that he was homozygous for the pathogenic c. $971 \mathrm{G}>$ A (p.Arg324His) variant in the GBA gene. He was provided supportive palliative care with high humidity, topical skin moisturizers, parenteral nutrition and antibiotics. He died from multiorgan failure at $22 \mathrm{~d}$ of life.

Gaucher disease (GD) is an autosomal recessive condition resulting from mutations in the glucocerebrosidase gene, causing deficiency of the lysosomal enzyme, beta glucocerebrosidase [1, 2]. The condition is characterized by the accumulation of lipid-

Gopakumar Hariharan

gopan2596@yahoo.com

1 Department of Pediatrics, Monash University, Clayton, Victoria, Australia

2 Department of Neonatalogy, Monash Medical Centre, Melbourne, Victoria 3168, Australia laden macrophages known as Gaucher cells that infiltrate the bone marrow, spleen, liver and occasionally the lungs resulting in multiorgan dysfunction $[1,3]$. In this case, the combination of hepatosplenomegaly, the timeline of presentation, thrombocytopenia, elevated ferritin and collodion membrane suggested perinatal GD.

The mainstay of treatment is enzyme replacement therapy (ERT) and substrate reduction therapy (SRT) which could be beneficial for other forms of Gaucher disease (e.g., visceral manifestation of neuropathic GD) but not for the lethal perinatal GD [2]. This case illustrates the importance of considering lethal form of Gaucher's disease in a Collodion baby and providing palliative care in these cases.

Acknowledgements We would like to thank Dr Risha Bhatia, Consultant Neonatologist, Monash Medical Centre for her constructive feedback.

\section{Compliance with Ethical Standards}

Conflict of Interest None.

\section{References}

1. Grabowski GA. Phenotype, diagnosis, and treatment of Gaucher's disease. Lancet. 2008;372:1263-71.

2. Gupta N, Oppenheim IM, Kauvar EF, Tayebi N, Sidransky E. Type 2 Gaucher disease: phenotypic variation and genotypic heterogeneity. Blood Cells Mol Dis. 2011;46:75-84.

3. Regenboog M, van Kuilenburg AB, Verheij J, Swinkels DW, Hollak CE. Hyperferritinemia and iron metabolism in Gaucher disease: potential pathophysiological implications. Blood Rev. 2016;30:431-7.

Publisher's Note Springer Nature remains neutral with regard to jurisdictional claims in published maps and institutional affiliations. 